\title{
Predicting the future
}

DOI:

10.2752/146069201789378450

\section{Document Version}

Accepted author manuscript

Link to publication record in Manchester Research Explorer

\section{Citation for published version (APA):}

Wilson, J., Benson, L., Bruce, M., Hogg, M., \& Oulton, D. (2001). Predicting the future: an overview of the colour forecasting industry. Design Journal, 4(1), 15-31. https://doi.org/10.2752/146069201789378450

\section{Published in:}

Design Journal

\section{Citing this paper}

Please note that where the full-text provided on Manchester Research Explorer is the Author Accepted Manuscript or Proof version this may differ from the final Published version. If citing, it is advised that you check and use the publisher's definitive version.

\section{General rights}

Copyright and moral rights for the publications made accessible in the Research Explorer are retained by the authors and/or other copyright owners and it is a condition of accessing publications that users recognise and abide by the legal requirements associated with these rights.

\section{Takedown policy}

If you believe that this document breaches copyright please refer to the University of Manchester's Takedown Procedures [http://man.ac.uk/04Y6Bo] or contact uml.scholarlycommunications@manchester.ac.uk providing relevant details, so we can investigate your claim.

\section{OPEN ACCESS}




\section{PREDICTING THE FUTURE:}

\section{AN OVERVIEW OF THE \\ COLOUR FORECASTING \\ I N D U S T R Y \\ 0}

JACQUIE WILSON, LOUISE BENSON, MARGARET BRUCE,

MARGARET K. HOGG AND DAVID OULTON

UNIVERSITY OF MANCHESTER INSTITUTE OF SCIENCE AND TECHNOLOGY (UMIST)

\footnotetext{
Tolour is so constantly in evidence in our lives that we are inclined to give it almost no conscious

attention.' (Guptill, 1980)
}

Colour influences all aspects of our lives, from the food we eat and the clothes we wear to the environment in which we work (Duncker, 1939). The colour of an item of apparel worn by someone has an impact on how they are perceived by others and how they perceive themselves. This means that consumers are extremely sensitive to colour when choosing apparel goods. There are several factors that influence colour choice, and while tradition and convention may for certain items dictate a restricted and well-understood colour palette, there are other items where there is considerably more scope for colour choice. This presents those with responsibility for merchandising decisions with a series of opportunities with regard to colour. There are however important implications for those making colour decisions. Choose colours that do not sell and the cost can be considerable with stocks of unsold garments on the shelves and purchases missed. The penalties for getting a colour range out of balance, or plain wrong can include loss of sales, profit and market share. Selecting the wrong brightness or chroma for a product may lead to losing market share to competitors who have achieved the correct balance of colours.

This paper aims to contribute towards a greater understanding of colour decision-making by considering some of the factors that influence colour selection decisions, looking at the services that are available to those making decisions about colour and analysing the processes involved in colour decisionmaking. An attempt will also be made to develop a strategic framework to assist in the management of colour selection. 


PAPEAS
PREDICTING THE FUTURE:
AN OVERVIEW OF THE COLOUR FORECASTING INDUSTRY

\section{INTRODUCTION}

\section{0}

Many researchers around the world are now recognizing the importance of colour in order to reach increasingly sophisticated customers on a deeper level (Benson et al, 1999). From the careful observation that 'emotions can be stirred by colour' (Tucker, 1987) to the more dramatic claim that 'whoever controls colour, controls the world' (Woodhuysen, 1994), it has been argued that "when colour has a specific, predetermined function that acts to support the overall strategy, your marketing effort can do all you've designed it to do.' (Geboy, 1996)

An understanding of colour and the factors influencing colour decisions is therefore important for those making decisions about colour

\section{FACTORS INFLUENCING COLOUR DECISIONS 00}

The reasons as to why people choose the colours that they do are complex and depend on a mix of various factors. These factors play a significant part in management decisions relating to colour choice, and the adoption by the buying public of certain colours as fashionable. However, for the buying public to be able to adopt any product or style the product or style must be available and advertised as such. What is available on the high street is the result of a series of exercises in selection:

- selection by manufacturers as to what initial design ideas to pursue through to a finished product at every stage - yarns, fabrics, garments and other textile products

- selection by retailers as to what items to include in their product ranges.

What the consumer ultimately decides to purchase is influenced by further selection exercises:

- further selection by retailers as to what products and styles within their ranges warrant special attention and promotion through in-store promotions and window displays

- selection by the media, press and television as to what will be promoted both formally through specific directional articles and programmes and informally through articles and programmes where products are seen to be used by those taking part

- finally there is of course selection by the consumers themselves.

The factors leading to the decision to purchase one item in preference to another include availability, affordability, desire and need. These factors themselves are influenced by other factors such as technology, geography, income, status and culture.

To try to make sense of all the factors influencing product choice, these can be grouped into six categories. It should be noted that these are often interlinked and interrelated. The six categories are aesthetic, cultural and traditional, social-psychological, economic and political, managerial, and physical. Can they be used to make sense of the factors influencing colour choice?

\section{AESTHETIC}

This category includes factors such as creativity, taste and what is considered to be attractive or beautiful at a particular time. The desire to decorate and improve our appearance could also be considered within this grouping. These factors clearly influence how colours are used together.

\section{CULTURAL AND TRADITIONAL}

Colours have different connotations and traditional uses across cultures and this can have a huge impact for manufacturers and producers. For example, in South-East Asia, where light blue symbolizes death and mourning, the 


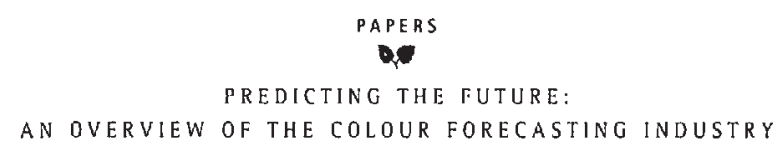

drink Pepsi-Cola lost its dominant market share to CocaCola when they changed the colour of their coolers and vending equipment from deep 'regal' blue to light 'ice' blue. Traditionally in the UK, pastel shades are associated with spring, bright colours for summer and dark shades for winter.

\section{SOCIAL-PSYCHOLOGICAL}

Factors in this category include self and group identity, personal expression, reference groups, group expectations/ peer pressure, role and social status. How people see themselves and how they wish to be perceived is often reflected in the colours they wear. Bankers wear sober dark grey business suits; they want to be seen as serious and grey is perceived as a serious, unexciting colour. If they were to come to work in bright coloured suits, they would be perceived as frivolous and it is unlikely they would be given business. Colours can therefore symbolize values.

Different psychological types show distinct seasonal colour preferences (Radeloff, 1991). Personality characteristics have also been shown to influence colour preferences, for example extraverts prefer warm colours and introverts prefer cooler colours (Eysenck, 1941).

A study of the colour preferences of older people (Sharpe, 1974), 90 people aged 65 to 89 , indicated that they prefer bright primary, secondary and tertiary colours to the pale pastels. Thus, those who paint every institutional wall in drab or pastel colours are quite mistaken in their belief that older people like these 'restful' colours. Misguided clothing manufacturers also invariably make dresses for mature ladies in sombre neutrals and pastels. This is unfortunate, as it has resulted in a kind of colour starvation in this age group. Interestingly this group actually tends to perceive bright, deep colours lighter than younger age groups perceive them.

\section{ECONOMIC AND POLITICAL}

Factors that come into this category include technology, production and distribution of goods, consumer demand, income and price. Colour has to be available, affordable and accessible. Historical and political events can have an affect on colours for apparel, for example the preference for dark sombre colours for clothing during a recession.

In years past, as people climbed up the social ladder or made money and achieved a higher status, they tended more and more to select pastels. One could thus conclude that with opportunity and advantage, a person's life was not so restricted and did not depend on immediate environmental stimuli. However, the shade and brightness of colours no longer distinguish social groups (Sharpe, 1974). With saturation affluence, even the rich are turning to bright, deep strong colours more and more. Could this be to escape from boredom? A desire to be young? The results are not yet conclusive.

\section{MANAGERIAL}

The factors included in this grouping include needs and desires, management of resources, buying habits and practices.

Colour can be used for product differentiation. Braun were renowned for using black and white for their products, however, the introduction of a new coffee maker not only in black and white, but also in red was a simple and effective way to mark the introduction of a new product. Many companies also use colour to differentiate between different models of products with different specifications.

\section{PHYSICAL}

Psychologists have discovered that merely by looking at different colours, blood pressure, along with heart rate and rate of respiration, can be altered (Wright, 1998). Pink has a 


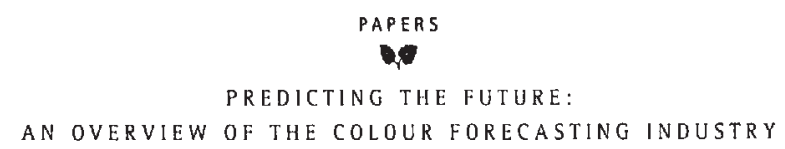

calming effect on stressed individuals and every theatre has a green room to help achieve a calm and relaxing atmosphere.

When a person approaches, the first thing that is noticed is the hue of their clothes. The nearer the wearer comes, the more space this hue occupies in the viewer's visual field and the greater the effect on their nervous system (Bruce and Green, 1990). Colours with a lower chroma value have a less intense effect on people.

Physical taste too can be affected by colour. Swiss research has shown that the same strength of coffee served in brown, yellow and red mugs was perceived to be different (Porter, 1990). In the brown mug the coffee was consistently recorded to be too strong, in the yellow mug too weak while in the red mug the coffee was considered to be just right.

Different climates, temperature changes and geographical location can also have an influence on colour. The way colour is perceived is dependent on the light under which it is viewed and individual colours are perceived differently depending on the surrounding colours. A bright orange shirt worn under a sunny sky in a lush Caribbean garden is perceived quite differently to the same shirt worn on a grey rainy day amongst the grey of city streets.

Small colour deviations can make a decisive difference to the psychological impact of a colour. For example, research indicates that dark-eyed people are much more sensitive to colour than light-eyed people. Itten (1961) reports that light blond types with blue eyes and a pink complexion usually prefer the very pure colours. People with black hair, dark skin and brownish-black eyes prefer to mix the pure colours with black (Wright, 1998).

\section{FUNCTIONS OF CLOTHING AND COLOUR 0}

Clothing has been said to serve four basic functions: to protect the body, to exalt the ego, to arouse emotions in others, and to communicate by means of symbols. Colour can also be considered as serving these basic functions. Colour clearly has an affect on how we feel and can be used to arouse emotions in others. Colour also communicates by means of symbols; obvious examples of this are the communication of allegiance to sports teams and political parties. Less obvious perhaps is the use of colour to protect but the bright fluorescent colours of the emergency services are used to protect by giving high visibility.

Colour is even used to describe emotion, with people being described as being green with envy or as seeing red. The use of colour in this way gives some idea of colour's abstract force. It is therefore of no surprise that colour has come to dominate many industries. The textiles and clothing industry is certainly no exception. Research work carried out by yarn and textile manufacturers, fibre producers, retail groups and trade fair organizers consistently shows that the first response by a customer, whether textile buyer or retail shopper, is to colour (Sharpe, 1974).

All consumers are influenced to some degree by fashion trends: this is due to the fact that the colours available in the stores are already limited, the result of the intensive process of selection referred to earlier. It is estimated that the human eye can distinguish over one million colours and clearly it would currently be impossible to offer this degree of colour choice in any product. This limitation in availability of colour to a range of 'fashionable' colours inevitably restricts consumers' choices. Few people realize the extent to which these 'fashionable' colours result from deliberate choices made by industry specialists, in a process known as colour forecasting.

Colour forecasting is the selection of ranges of colours that are deemed as those that will be wanted for a particular product/market at a particular time in the future. Many colour forecasts are specific to specific product ranges, 


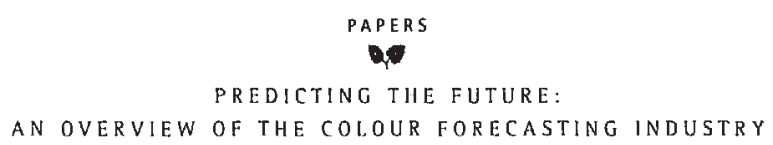

men's knitwear, children's leisurewear etc, but most will show three colour groupings: pales, mediums and darks. Within these groups there are likely to be several colours referred to as classics /colours which have been accepted over a long period of time such as camel, navy, bottle green and black). As the vast majority of consumers do not replace their wardrobe every season, colour ranges for a specific season must take into account the colours of the previous seasons as well as what might be described as new 'fashion' colours. Any colour palette will normally therefore show within its pales, mediums and darks some of the previous seasons' fashion colours, the new season's fashion colours and some classics.

It has been demonstrated that there are many factors that affect consumers' colour choice. With increasing consumer awareness regarding the use of colour, it is critical that companies understand these factors and how they affect their particular market. Marketers need to understand the effect that colour has on consumers and colour forecasting in order to deliver appropriate colours for their particular market. Even a slight difference in shade from what is required by the final consumer can be catastrophic to the manufacturer.

Is there a range of colours that a textiles company can use each season, with only simple adjustments to the shades? This has worked for designers such as Armani, who uses a palette of basic colour such as grey, blue, black, beige and white. Could this simplistic range of colours ever work for high street retailers? (Benson et al, 1999) Could colour selection for a specific product range ever be done scientifically, mapping colour change on a scientifically developed three-dimensional colour model?

The rapid development of technology offers the prospect of bringing together information and precision colour technology that is presently considered fragmentary

and difficult to coordinate in a concerted effort to improve the process of optimizing product colour.

\section{INFORMATION AVAILABLE FOR COLOUR FORECASTERS AND HOW THIS IS CURRENTLY USED IN PRACTICE ae}

A series of semi-structured interviews was conducted with several companies within the textiles industry. Those interviewed included colour consultants, fibre suppliers, manufacturers, design professionals and retailers. The interviews covered several key areas: the development of colour forecasting for the UK market, timescales from initial concept of a colour palette through to the consumer, the different types of information used by companies, what sources of inspiration were currently available, the costs involved in forecasting, and the importance given to the ultimate consumer.

The duration of each interview was approximately one hour and all interviews were recorded and transcribed with the consent of the interviewee. The findings are presented in order of occurrence within the supply chain, starting with information from international and national colour meetings through to information from retailers and consumers.

A large mail order company was identified for in-depth study and interviews were conducted with key employees there to identify when and where colour decisions were made and to discover what problems were experienced with colour decision-making.

Information was also collected from trade shows such as Première Vision, conferences including Design Foresight and secondary sources such as trade magazines.

"The word "fashion" is synonymous with the word "change". Fashion begins with fabrics and fabrics begin with 
colour. Each season colour must make a new statement for fashion to continue its natural evolution. Our eyes need refreshment. We may have disliked the way we looked in last season's clothes, but this season offers the opportunity to wear new colours, groom differently and appear as a new person. And if we are still dissatisfied, three months later there is a new season.' (Horn, 1981). This quotation is from Ed Newman of the American Textile Manufacturers' Institute. If we don't like our surroundings, textiles can help us effect a transformation and if we don't like that we can adopt the next trend to come along.

Designers are working for the future: they try to predict what the market they are designing for is going to want. Designers can find themselves working on a product range anywhere from six months to two and a half years ahead of season.

If we consider the fabrics and fashions for any retail season, the designers who styled the garments would have been working on them 7 to 12 months before, the fabric designers would have been working on their ranges 12 to 15 months before, the yarn designers 18 to 20 months before and the colourists approximately 24 to 25 months before. The timescale for forecasting colour trends from the initial concept to the garments retailing in the shops is therefore approximately two years. This timescale is illustrated in Figure 1.

\section{INFORMATION AVAILABLE FOR THOSE INVOLVED IN COLOUR DECISIONS 0}

As might be expected, the earlier in the supply chain the less information there is available to help with colour decision-making. For those wanting information 20 to 24 months in advance of the retail season there is little available and what is available is expensive.

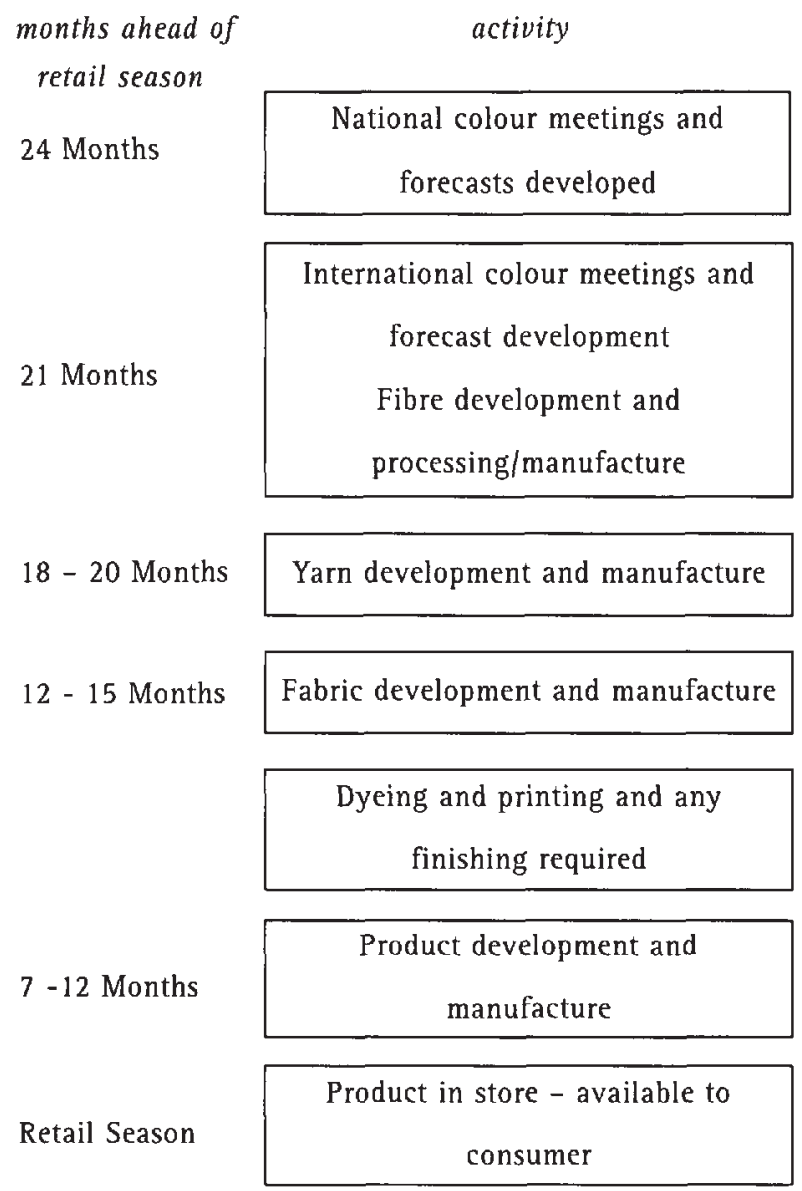

Figure 1: Timescale for textile product design/manufacture ahead of the retail season.

\section{COLOUR FORECASTING PUBLICATIONS}

There are several colour forecasting publications available to textile companies including those by ICA (International Colour Authority) and Design Intelligence. These commercial forecasting services provide global forecasts predicted to be popular for an impending retail season. This information is initially not specific to particular customer groups although packages such as that offered by ICA will show different colour palettes for menswear, womenswear, childrenswear and home furnishings. As well as the organizations detailed other organizations offering forecasting publications commercially include Modatessuto and L'Officiel de la Couleur et Textiles. 


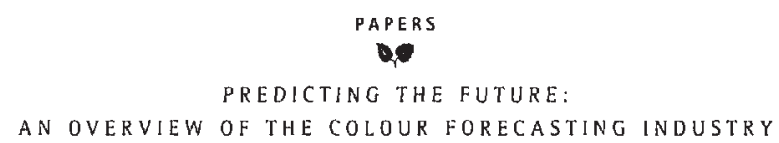

\section{THE INTERNATIONAL COLOUR AUTHORITY (ICA)}

The International Colour Authority (ICA) was launched in September 1968. A commercial organization, the ICA publishes colour predictions up to 22 months ahead of the retail season. The forecast colour ranges are developed by a panel consisting of 30 of the world's most experienced colourists and designers who gather every six months to discuss colours for the forecasts. Various methods are used to source colour ideas and influences on colour can come from virtually anything. Inspiration may come from society, the mood of the time and even what is happening politically and on the streets. The forecasters on the panel come from all over the world from many ethnic backgrounds. This is intentional, to ensure the global validity and scope of the group. The panel predicts directional colours for womenswear, menswear and furnishings. The impressive ICA portfolio is highly regarded by industry and is the earliest colour predictive service.

All information discussed and compiled by the panel is kept secret until the final stage of development. Subscribers pay such high fees for the predictions that they rarely discuss the results. After all, their aim is to put themselves one step ahead of their competitors. The colour forecasts consist of colour mood boards, colour palettes, some styling ideas, and fabric swatches. Key colours, accents, images and collages are displayed to reflect the feeling and atmosphere of a specific season. These colour palettes are intended to allow for individual interpretation by subscribers.

\section{DESIGN INTELLIGENCE}

Design Intelligence is a London-based design service. Using similar methods to the ICA they forecast colour, yarn, fabric and design trends for their customers. They cater for an international market and publish forecasts every six months.
The success of Design Intelligence lies in the fact that the service is applicable to all types of manufacturer, whether large or small (Benson et al, 1999) The services offered are costly but they supply detailed and relevant information that can give their customers a competitive edge.

\section{CARLIN INTERNATIONAL}

Carlin International is a Paris-based colour-forecasting company. Their publications carry similar information and are comparable in cost to those produced by Design Intelligence. The colour forecast books from Carlin International are available 16 months ahead of a season.

\section{INFORMATION GENERATED BY TRADE SHOWS Qe}

Colour forecasts for trade shows are devised on the same basis as colour forecasting publications although these tend to cater for the requirements of buyers rather than designers. The forecasts shown at trade shows generally act as a form of confirmation for the colours predicted by colour consultants and colour prediction publishing companies earlier in the season. This is perhaps unsurprising as the trade shows are working with the same information as companies such as ICA and indeed will often have access to ICA and other publications. With the exception of Première Vision, the textile supply chain dictates the order in which shows take place. The first shows are the yarn shows, followed by fabric shows through to garment shows. The following section highlights some of the key trade shows in the industry.

There are several international fibre and yarn shows held every season. Expofil is a trade show that is held every six months in Paris, two months ahead of other fibre and yarn shows. Pitti Filatti is another fibre and yarn show, held in Florence with exhibitors representing leading yarn spinners for knitwear and the major fibre producers. At Yarn 


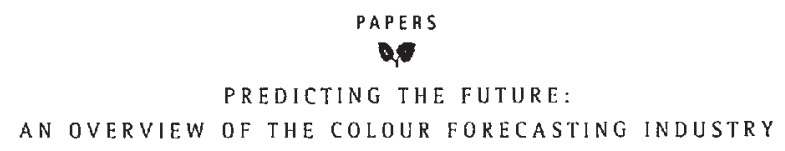

Collections in the UK (formerly the British Yarn Show) exhibitors are knitting yarn producers and fibre producers.

The earliest fabric show is Première Vision, held in Paris twice a year, one year ahead of the retail season. The colours agreed by the Première Vision consortium are displayed in trend areas at the exhibition. There are also audiovisual screenings to highlight key colours for the season. A magazine to encourage the ideas that have been highlighted accompanies the screenings. Another important fabric show is Interstoff. This is held in Frankfurt twice a year and lasts for three days. As with Première Vision, the trends are presented in specific areas and act as confirmation on directions for designers. Again those responsible for determining predicted colour palettes at these fabric shows have had access to the same information as those before them.

Several garment and fashion shows are held each season which include information on future colour directions. Prêt à Porter is a notable garment show for women's apparel that is held every six months in Paris. Salon Européen de l'Habillement Masculin (SEHM) is a menswear show held at the same time, again in Paris. These trade shows are enormous in size with many hundreds of exhibitors and are extremely popular with European manufacturers. Essentially directed towards buyers, they are also helpful for designers gathering colour and styling trend information and observing the sales of the different products.

Trade shows provide colour predictions that are more market specific, but they still lack that personal edge.

\section{INFORMATION AVAILABLE FROM COLOUR CONSULTANCIES Q}

Colour consultancies provide forecasts and trend guides for customers in a variety of product areas. They interpret trend information and tailor colour ranges to narrower and more applicable colour stories for their client's individual product/market area. They are increasingly contracted to assist manufacturers' in-house design teams, bringing an objective approach to the selection of colour, to enhance the sales potential and perceived value of products.

\section{PROMOSTYL}

Promostyl is a colour consultancy and styling bureau. It is based in Paris and has over 20 branches worldwide. Ideas are gathered from all over the world and compiled at the head office in Paris. Promostyl produce fashion styling and colour forecasting books as well as working for individual clients. Colour directions are obtained from numerous sources. The fees are substantial, prompting debate over how accurately predicted demand for colour can really be forecast. While there can be no guarantees, careful research into market sectors and an awareness of design and colour trends combined with new technology guarantees the procurement of an invaluable database. Integrating this data with creativity and some degree of intuition gives rise to a reasonable air of confidence. While one colour consultant admits that they do not always get it right (Moreton, 1984), another company specializing in colour research has a more optimistic view, 'We research reactions not just to primary shades but to tone and texture. On the basis of our tests, we can forecast sales of colours of a new product with at least 90 per cent accuracy'. (Benson et al, 1999)

Although colour consultancies create colour palettes for specific markets, there are ways that they could get closer to the customer. A great deal of research has been carried out into colour preferences, including aspects such as gender preferences (Braun and Bonta, 1979), age preferences (Horn, 1981) and preferences relating to income (Sharpe, 1974). If 
these consultancics carried out more research into consumers' colour preferences, it would provide a more powerful service for their customers.

\section{BRITISH TEXTILE COLOUR GROUP}

The British Colour Council (BCC) was set up in 1931, consisting of colour experts representing British companies who provided seasonal colour predictions. In 1974 the BCC collapsed and in 1976 the British Textile Colour Group was formed. Although not strictly a consultancy or a commercial publisher with procedures akin to the ICA, the British Textile Colour Group works 28 months ahead of the retail season. The final result is colour forecasting that is multinational and consequently extremely marketable.

\section{INFORMATION FROM TEXTILE ORGANIZATIONS a.}

Several trade organizations, including the International Wool Secretariat and The British Knitting and Clothing Export Council hold regular trend seminars for a variety of market sectors. The seminars were set up to help UK manufacturers research fashion elements of their range for internal and export markets and are a valuable source of information.

Trade seminars attract representatives from the retail sector and delegates from other sectors of the textile industry including fibre producers and yarn, fabric and garment manufacturers. Presentations concerning colour and styling trends are highly detailed and provide a reliable basis for each season's range. offered as a service to the members, the relatively low costs of trend seminars mean that these are far more accessible to companies than most of the services offered by colour forecasting publishing companies and colour consultancies, and visiting expensive trade shows.

\section{INFORMATION FROM TRADE PUBLICATIONS} QP

For many companies, trade magazines carrying features on trend information from shows are an important source of trend information. These reports come at a much later stage than initial colour forecasts, however they are an important and cheap method of confirmation of colour ideas.

Although these sources provide colour selection guidance for companies at a cheaper rate, the palettes shown are usually still very general with limited relevance for very specific market areas.

It is clear when considering the information sources available with regard to colour forecasting that designers and buyers are influenced by and have access to similar information. It is perhaps hardly surprising then that there is generally some degree of consensus among retail as to which colours are promoted as 'fashionable' for any season.

Colour is at the very heart of our existence and can alter our perceptions of the world. As previously noted, consumer's awareness of the power of colour and how it can fundamentally influence their lives is increasing (Wright, 1998). Consumers are becoming more focused on what colours are right for them in given situations, regardless of society's pressures. This means that consumers' power over the industry is increasing. Companies need to react to this by introducing some strategy within their colour selection process that takes into account consumers' tastes.

Research has shown that a fashion buyer's personal colour preferences influence the colours used in their range (Wright, 1998). This means that a company must either chose a buyer with similar preferences to the target market or ensure that the buyer has the necessary knowledge and skills to enable them to select colours to suit the tastes of their specific market. The tastes and colour preferences of target groups can be identified to some degree from analysis 


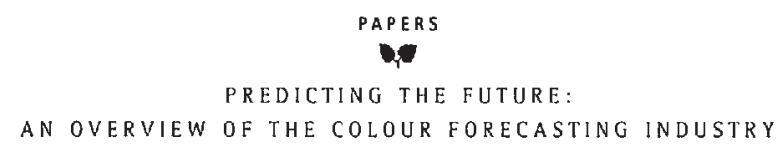

of past sales and by using focusing groups to try to identify lifestyles and directions.

\section{CONSUMER PREFERENCES \\ ae}

'There is an incredible number of people who fight against the use of colours - but there are also many people who fight against common sense.' (Panton, 1997)

Consumers are the final link in the process of colour selection. Their desires and needs are what drives the whole process and so fundamentally they must be the most important consideration. The role of fashion and its importance to the consumer has changed dramatically over the past decade (Benson et al, 1999). Today, designers are working for a world bursting with social, political and ecological changes. After the conspicuous consumption of the 1980s, key issues for the consumer have been based on traditional values such as authenticity, quality, commitment and service. Individuals now seek more control over their lives, greater value to what they do and more personal freedom. Today's consumers are less motivated by money and material possessions, the status symbols of the 1990 s. Today's consumer has become more confident, discerning and able to make their own judgements and individual decisions concerning fashion messages through the media (Barker, 1998).

'We are no longer trying to attract attention so we have a different idea of status. Today luxuries are for yourself and not just for the outside world. It is more about expressing their values for themselves.' (Barker, 1998)

'We are entering a period of new ethic awareness. The consumer is going to look at a company he is buying from and ask 'Is this an honest company? Does it make quality merchandise? Is it charging me a fair and honest price for what I am buying?' It is not for nothing that more retail stores are getting increasingly involved in charity work and fundraising.' (Shah, 1992)

\section{COLOUR SELECTION DECISIONS \\ - the PRACTICE IN INDUSTRY

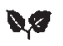

Most companies do not appear to have a formal system in place to aid successful colour selection. Rather colour decisions are made in a very informal and rather ad hoc manner.

Designers (when a company employs a designer) often have the responsibility of making colour decisions. However, previous research by the authors has shown that some companies do not even use designers to make their colour decisions. One mail order company, whose colour selection process was studied in some detail, uses their buyers for the ultimate colour selections within the organization. While this could be seen as a disadvantage, as design is only one aspect of the buyers' role, it does, however, eliminate the problems associated with buyers misinterpreting the designers' forecasts. Garment manufacturers may use colour consultants; this is often to provide reassurance that initial in-house colour selections are right. Designers particularly report that specific forecasting publications are of great help. However, with the exception of fibre producers, an overwhelming number of companies do not use them (Shah, 1992). Many companies perceive the costs of such publications as being too high and so many designers have to find alternative information sources such as trend articles in the trade press. For many organizations such articles come too late.

Evidence exists to show that many companies in the UK textile industry use more than one source of inspiration for colour forecasting at any one time (Kirby, 1994). Increasing inputs reduces the chance of getting the wrong shade, leading 
to higher prospective profit. Many companies feel that it is important to spend a great deal of time on colour forecasting, but we found that very few companies feel that it is necessary to spend large sums of money on colour forecasting.

While designers are often responsible for selecting colour ranges, this is usually in collaboration with buyers and others who can input additional information and give reassurance that the direction being followed is the right one. Colour forecasting in apparel is reported as becoming more vital for international marketing (Benson et al, 1999). Exports play a significant role in the economies of most countries, therefore the industry must be constantly informed of developments abroad. Colour allows companies to establish a national identity in international markets.

Figure 2 shows the process of colour decision-making for a UK mail order company. This is a fairly typical pattern although there is a wide variety in the way organizations do select colour palettes.

The mail order company studied subscribes to Design Intelligence, however the information received is on style forecasting, rather than colour forecasting. The Head Buyer attends Première Vision to analyse the colour and style trends. The information is then fed back to the buying team in the form of an initial colour and style meeting which also incorporates information from catwalks, trade publications and previous sales. The initial meeting is regarded as an idea generating session with buyers then conducting comparative shopping trips in locations such as New York, Paris, Milan and London to see what is being shown as fashion there, depending on their particular range.

The main colour palettes for the season are presented by the Head Buyer at a second meeting. This usually covers a range of classic, fashion and neutral colours. Garment manufacturers suggest colour palettes that they think will work for the forthcoming season. The garment manufacturers

\section{Initial Colour Research}

Carried out by the Head Buyer (Première Vision, catwalks, trade publications, previous sales)

Initial Colour and Style Meeting

Head Buyer interprets information and ideas

are generated

\section{Comparative Shopping}

Buyers analyse trends in suitable locations for their range

Second Colour and Style Meeting

Discuss main colour palettes and competitor information

Buyers' Proposal

Includes colour and style directions for the season

\section{Strategy Meetings}

Merchandise strategy and overall company strategy

Buyers' Workshops

Discuss details of the range, analysis of past sales, competitor purchasing behaviour etc.

Product Sourcing

Figure 2: The process of colour decision-making within a mail order company (Source: Benson et al, 1999).

also gather substantial information on colour trends, and these will hopefully confirm the colour palettes that the buyers have produced. Figure 3 highlights the main sources of inspiration that are available to buyers to assist them in producing their colour palettes.

Recent developments in the electronic transmission of precise colour specifications (Oulton et al, 1996) have been reported. Rapid and accurate colour communication is potentially regarded as a key contribution to improving the process of colour forecasting, and its wider use. 
The mail order company studied did not consider colour management to be a high enough priority to justify substantial investment in colour forecasting services. It also carried out limited consumer research. Given the importance of getting colour right this is surprising particularly when it is considered that mail order companies only produced ranges twice a year while fashions can change every six to eight weeks. Also there are limitations on the colours that can be reproduced in a catalogue, due to problems associated with photographing certain colours. If a garment is not reproduced accurately in the catalogue, this may result in high return rates

\section{DEVELOPMENT OF A}

\section{STRATEGIC FRAMEWORK}

\section{0}

How do the designers know what people will want? What is 'in fashion' is constantly changing. Where do designers find directions and ideas for their new ranges and can some model or strategic plan help get this process right?

As we have seen, the goods available in the shops are the result of an intensive process of selection within the fashion and textile businesses: selection by designers as to what they actually sample, selection by buyers and selectors as to what they buy and selection by the consumer as to what they actually purchase. The fashion press also select what they will show and promote, and it should never be underestimated how important a role the press play in spreading particular styles.

The majority of designers work under quite considerable constraints. Certainly in the mass market they are often trying to produce designs which correspond to already identified trends.

Ideas produced by designers undergo a ruthless process of selection by the designers themselves and within the producing company. The aim is to identify those designs most likely to be successful, that is, those that correspond most closely to the anticipated fashion as well as working within production and cost constraints.

The key for anyone making colour decisions is to be as aware and as informed as possible. Knowledge of the market is important; those responsible for colour must get out and about to see what is on offer. What is selling now? What has sold in the past? Can any trends be spotted from the data gathered, any conclusions drawn? Who are the competition, what are they doing and how successful are they? Magazines can help here.

They must have access to sales figures. What colours/

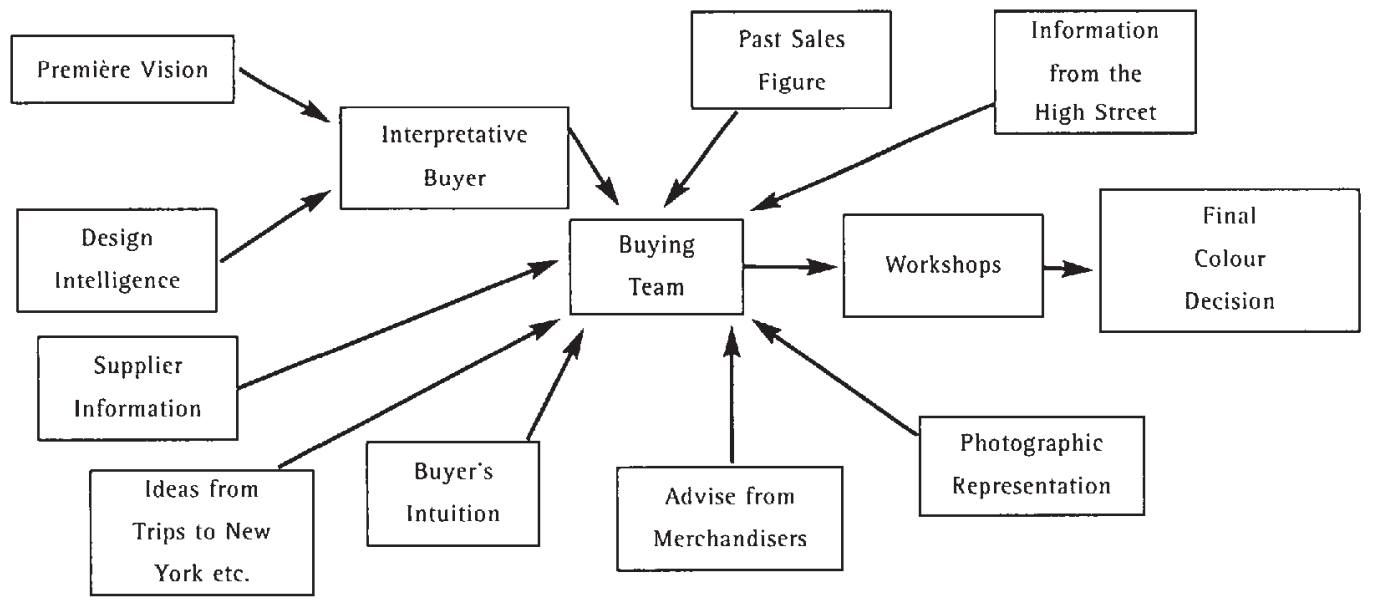

Figure 3: Colour selection information (Source: Kirby, 1994). 
fabrics/styles are selling well or have sold well in the past? The sales team should constantly feed back information to design. Who exactly is the customer? What is their lifestyle?

An understanding of the factors which influence fashion is essential to help recognize those that are likely to influence future fashion. The media - television, radio and the press - and theatre and cinema have a great influence on the buying public. In particular television and the cinema have a great deal to do with the acceptance of new styles by consumers. James Dean in the film Rebel Without a Cause wore a white tee-shirt and denim jeans, setting a fashion that was to become a classic.

An awareness of what is happening in the world of cinema and television is also required. Who are the personalities in the news? In their time Elvis Presley, the Beatles and Jackie Kennedy have all had a tremendous influence on fashions. People love to emulate the personalities they admire.

What exhibitions or events are happening? What artists are in the news? Art collections on world tour often have an influence on fashions. When the Matisse and Chagal exhibitions were on tour and in the media spotlight many areas of design reflected the styles of these painters.

What new technologies are available? The 1960 s fashion for easy-care fabrics could not have come about had the man-made fibres with the necessary properties not been developed.

Designers also influence fashion. What is happening in the world of design? Who are the leaders? Dior in 1947 gave the fashion world the 'New Look', Courreges in the 1960 s started the space-age looks that became so popular with his minis and white plastic boots. Vivienne Westwood gave the fashion world the mini-crini.

Those making colour decisions ideally should have access to forecasting services from organizations like the
ICA, Design Intelligence, Carlin International and Promostyl. Attendance at trend seminars such as those held by the British Knitting and Clothing Export Council (BKCEC) are helpful. The International Wool Secretariat (IWS) and the International Institute for Cotton provide promotional forecasting services for their respective fibres as do the synthetic fibre producers. The yarn spinners advise their customers - the fabric manufacturers - on the trends as they see them, the fabric manufacturers in their turn advise their customers, the garment manufacturers and so on.

At every stage in the process involved in producing textile products there are trade shows where there is the opportunity to see the forecasted directions from a wide spectrum of sources. Trends are edited and refined at each stage of the manufacturing process.

It can be seen that many influences must be taken into consideration when predicting future trends; these include consumer moods, the political and economic climate, global trends, environmental issues and technology. Colour forecasters need to be aware of international influences and constantly absorbing the world around them. However, although consumer moods are considered, this is often in a global context, and forecasters should also consider aspects such as preferences for particular consumer groups.

The importance of consumer preferences in colour selection indicates the need to develop a strategic framework to aid companies understand the concept of consumer tastes, rather than basing judgements on individual beliefs. So from all this information how can a framework be developed to help companies? What follows is an attempt to put together a model for the colour forecasting process which could be adapted to the requirements of any individual company. 


\section{DISCUSSION}

\section{0}

This model identifies four main types of information required by those making colour decisions.

- Information about colours predicted by others.

This includes commercially available information, information from trade organizations, information from suppliers (not available for fibre manufacturers) and information about colours predicted by others.

- Information about what is popular now. Included in this is information from the media - trade magazines and popular magazines, TV and cinema, information from retail organizations - what is selling and observed, information from the streets - what is being worn/ used now.

- Information from within the organization. Information here includes that from sales and other designers within the organization.

- Information about target market: This includes commercially available market research, and primary research through questionnaires, focus groups.

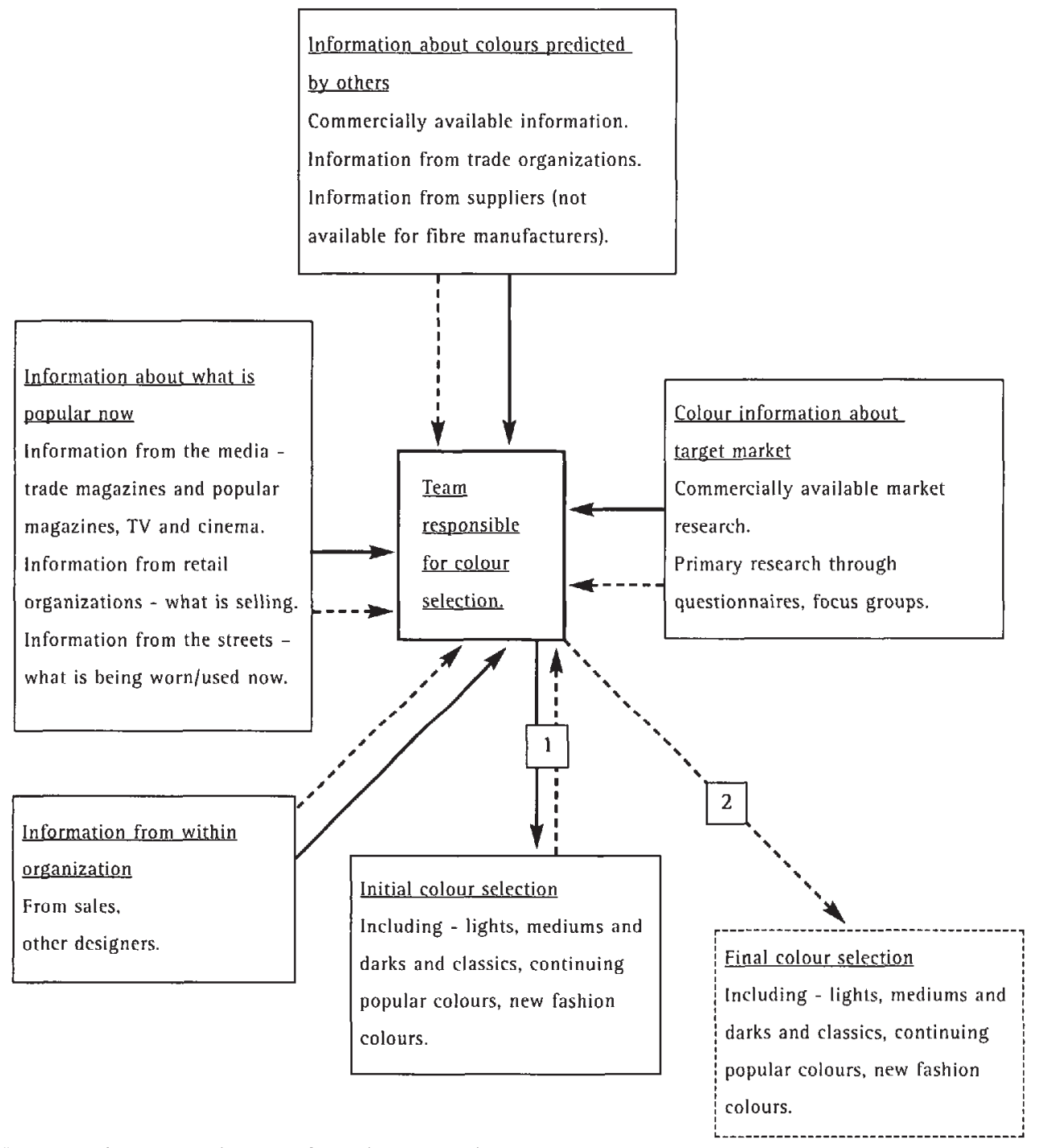

Figure 4: A suggested model for colour selection. 


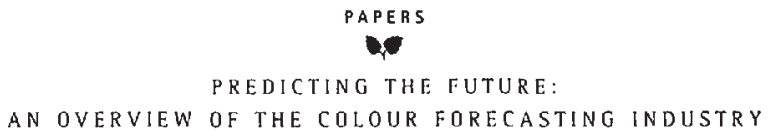

All four types of information are necessary for those making colour decisions. The information from these four areas is fed in and the team responsible will make initial colour selections. Any initial selection for a colour palette would normally include ranges of lights, mediums and darks and classic colours, continuing popular colours and new fashion colours.

Rather than these being the final colour decisions the team should constantly be receiving information from all four identified source areas, amending and refining the initial colour selection until a time when it is impractical to change colours is reached, the colour selections at that time becoming the final colour selection. Again this final colour selection would normally include ranges of lights, mediums and darks and classic colours, continuing popular colours and new fashion colours.

\section{CONCLUSION}

\section{0}

'Choosing colours should not be a gamble. It should be a conscious decision. Colours have a meaning and a function.' (Panton, 1997)

This paper highlights the fact that the element of consumer preference in colour selection should not be based on intuition but on understanding, based on empirical observation and analysis of consumer tastes. The power of the consumer in colour selection is increasing as individuals become more articulate about their personal preferences. Companies can no longer dictate the colours that their customers wear. While colour can often be taken for granted both by suppliers and their customers, and many companies follow trends that are developed by forecasters, is this actually what their customers want?

If colour is so critical to company success, should colour be introduced as a new marketing mix variable?
The marketing mix 'product' incorporates colour, however, considering the importance of colour to the success of a product, it may be useful to separate these two variables.

Companies need to develop a formal strategy for colour selection at all stages of the supply chain to ensure that the customers' needs and wants are satisfied to the best of the companies' abilities. This article gives some basic information to help companies develop a suitable framework for their particular markets.

Colour forecasters provide colour choice for a season, but the final decision lies with the buyers. Buyers tend to be market led, and it was felt that this makes them rather conservative in their selection and lack of innovation on the high street and in mail order catalogues may be a reflection of this (Sander, 1998). Few manufacturers or retailers want to move away from the mainstream and take risks, although moving away from the mainstream and developing different colour palettes for their particular market may help to reduce risks in the long run and increase sales, market share and profit.

The element of consumer taste in colour selection should not be based on beliefs but on knowledge based on empirical observation and analysis of consumer tastes. Although taste is a complex phenomenon this can be done. But is has to be remembered that reflexivity, the opening to question of the designer's own concepts of taste, is a fundamental issue in the selection process where customer taste is taken into consideration.

The aspects of taste and the critical, reflective and iterative way of proceeding described in this article should aid companies to develop a framework for the analysis and synthesis of consumer taste in the process of colour selection. 


\section{REFERENCES}

\section{Q.}

Barker, R. (1998). An analysis of colour and style forecasting. BSC Thesis, Department of Textiles, UMIST, UK. April.

Benson, L., Bruce, M., Oultan, D., Hogg, M. and Wilson, J. (1999). 'The art of colour forecasting: A summary of colour forecasting in the textile and clothing industry and its influence on future predictions for a UK mail order company: The International Journal of New Product Development and Innoutions Management, 1 (4), $311-320$.

Braun, C. M. and Bonta, J. L. (1979). "Cross-cultural validity, reliability and stimulus characteristics of the Lüscher Calor Test: Journal of Personality Assessment, 43 (5), 459-60.

Bruce, V. and Green, P. R. (1990). Visual perception - Physiology, psychology and ecology (2nd Edn.). London: Lawrence Erlbaum Associates.

Duncker, K. (1939). 'The influence of past experience upon perceptual properties: American Journal of Psychology, 52, 255-267.

Eysenck, H. J. (1941). 'A critical and experimental study of color preference: American Journal of Psychology, 54, 385-394.

Geboy, L. D. (1996). 'Color makes a better message'. Journal of Hcalthcare Marketing, 16 (Summer), 52-54.

Guptill, A. L. (1980). Color manual: For artists (Ed. Sullivan, C.J. London: Van Nostrand Reinhold.

Horn. M. J. (1981). The second skin - An interdisciplinary study of clothing. Boston, MA: Houghton Mifflin Co.

Itten, J. (1961). The art of colour (118-119). New York: Rheinhold Publishing Corp.

Kirby. N. L. (1994). Colour forecassing - An analysis of trends in women's apparel. MSc Thesis, Department of Textiles, UMIST, UK. September.

Moreton, A. (1984). 'Choices that colour the future: Financial Times, 29th December.

Oulton, D. P, Porat, I., Boston, C. and Walsby, R. (1996).

Imagemaster: Precision colour communication based on CIE calibrated monitor screens: Procedings of the 5th International Conference on High Technology: Imaging Science (290-297). Chiba, Japan, September.

Panton, V. (1997). Notes on colour. Copenhagen: Dansk Design Center. Porter, T. (1990). The language of colour. Slough: Colour Dimensions (ICI Paints).

Radeloff, R. (1991). 'Psychological types, colour attributes, and colour preferences of clothing, textiles and design students: The Clothing and Textiles Research Journal, 9, 59-67.

Sander, J. (1998). 'Undressed: Channel 4 Documentary, 1st March.
Directed by Jaki Judelson.

Shah, D. (1992). 'Making sense of no sense', Expofil News, Promotional Material.

Sharpe, D. T. (1974). The psychology of color and design. Chicago: Nelson-Hall.

Tucker, J-V. (1987). 'Printing: Psychology of color'. Target Marketing, $10(7), 40-49$.

Woodhuysen, J. (1994). 'Add lacal colour and understand your consumers': Marketing, June 23 rd, p.7.

Wright, A. (1998). The beginner's guide to colour psychology. London: Kyle Cathie Limited.

\section{BIOGRAPHY}

\section{Qte}

Jacquie Wilson is a lecturer in textile design and design management in the Department of Textiles, University of Manchester Institue of Science and Technology (UMIST), Manchester, UK. A graduate of the Scottish College of Textiles, she spent ten years in industry as a designer before going to UMIST in 1984. Current teaching areas include all areas of textile desígn, woven fabric structures, design enterprise, professional practice of design and the design process. Research interests include forecasting, the design process and the teaching of textile design.

Louise Benson is a graduate of the BSc Honours degree course in Management and Marketing of Textiles in the Department of Textiles at UMIST, where she is currently studying for a PhD in the area of colour psychology.

Professor Margaret Bruce is currently Head of the Department of Textiles at UMIST. She is a professor of design and design management and has published 5 books and over 200 papers in these fields. Current rescarch interests include e-commerce and design and innovation management in the supply chain.

David Oulton is the leader of the Precision Colour Communication Research Group in the Department of Textiles at UMIST.

Dr Margaret Hogg is senior lecturer in Consumer Behaviour at Manchester School of Management, UMIST. After postgraduate studies in Amsterdam and Lancaster, she spent six years working in marketing prior to joining UMIST in 1985 Research interests include consumer behaviour, retailing and marketing history. 


\section{ADDRESSES FOR CORRESPONDENCE}

\section{0}

Jacquie Wilson, Department of Textiles, UMIST, P.0. Box 88,

Manchester M60 10D, UK.

Tel: $+44(0) 1612004146, f a x+44(0) 1619558157$.

Email: Jacquie.Wilson @umist.ac.uk

\section{ACKNOWLEDGEMENTS}

\section{0}

This research was funded through the Engineering and Physical Sciences Research Council's Casc Award. The authors would like to express their appreciation to the EPSRC for this funding. They would also like to thank an anonymous mail order company for their funding and information on calour selection within their organization. 